\title{
Algunos problemas relacionados con las ilustraciones en las traducciones de una obra clásica de la literatura infantil y juvenil: el caso de Caperucita Roja en España
}

\author{
Hanna Martens \\ José Soto Vázquez ${ }^{* *}$
}

\section{Resumen}

En una edición ilustrada de una obra literaria los elementos verbales se combinan y completan con el aspecto visual del volumen para transmitir su mensaje al lector. Al traducir la obra a otro idioma, se intenta, en la medida de lo posible, respetar el equilibrio establecido entre la información proporcionada en el texto y en las imágenes. Si se trata de una obra clásica, sin embargo, que se sigue editando a lo largo de varios siglos, la situación suele complicarse, ya que, como es habitual, no sólo se realizan nuevas traducciones, sino que también van cambiando las ilustraciones. Este es el caso de las traducciones españolas del cuento de "Le Petit Chaperon Rouge" (Caperucita Roja) de Perrault. Las ilustraciones han tenido una importancia innegable en la recepción de la obra, creando cierto ambiente y completando las caracterizaciones de los personajes. Así, algunas ilustraciones se han mostrado particularmente influyentes, no sólo dejando su huella en los ilustradores de las generaciones posteriores, sino llegando a introducir también modificaciones en las traducciones del propio cuento. Además, es tal el poder de las imágenes que llegan a manipular el contenido de la obra, destacando ciertos elementos en detrimento de otros o defendiendo abiertamente cierta ideología. A veces, incluso, pueden llegar a producirse incongruencias entre el texto y las imágenes que lo acompañan.

Palabras claves: Traducción. Ilustraciones. Literatura infantil y juvenil.

\footnotetext{
* Profesora ayudante en Universidad de Extremadura (España).

** Profesor contrato doctor en Universidad de Extremadura (España).
} 
En la edición ilustrada de una obra literaria los elementos textuales se combinan y completan con el aspecto visual del volumen para transmitir su mensaje al lector. Si se trata de un libro para un público joven, lo visual cobra aún más importancia: el nińo que todavía no sabe leer, se limita a escuchar lo que un adulto lee y observar las ilustraciones que acompañan al texto. En ocasiones, incluso volverá a ojear el libro recordando y reconstruyendo la trama desde las imágenes que figuran, sin la ayuda de un adulto.

A la hora de pasar un libro ilustrado a otro idioma, O'Sullivan (2006) indica que la traducción ideal refleja conscientemente la interacción entre los elementos visuales y verbales y respeta el equilibrio entre la información proporcionada en el texto y en las imágenes para que al lector le reste el mismo trabajo por hacer que al lector del original. La situación se complica, sin embargo, si la nueva versión llega a adquirir el estatus de "clásico" y, como tal, se sigue editando a lo largo de varios siglos. En estos casos es común que no solo se vayan produciendo nuevas traducciones, sino que también vayan cambiando las ilustraciones (PEREIRA, 2008). Es exactamente lo que ocurre con el cuento de "Caperucita Roja" de Perrault.

En términos de la estética de la recepción, cuyos principales ideólogos son Hans Robert Jauss (1986) y Wolfgang Iser (1987), en la tradicional tríada de productor (autor), producto (texto) y consumidor (lector), la importancia del lector se ve priorizada como componente activo que construye el significado del texto. En un lugar indeterminado que Iser, siguiendo a Ingarden, denomina como espacio de indeterminación, la información que aporta el texto confluye con la imaginación, la emoción y el sentido crítico del lector, dando así origen al particular significado que cobra el texto para el lector en cuestión (ISER, 1987). Ball Vargas y Gutiérrez (2008) nos enseñan que esta dinámica de la recepción de la literatura se produce incluso en los niños que todavía no saben leer. Del mismo modo que el adulto que lee una obra literaria, el pequeño receptor construye su significado del texto vinculando lo que oye y ve en las imágenes con lo que conoce y sabe. En el caso de los cuentos de Perrault, podemos, por lo tanto, hablar de un múltiple proceso de recepción: el significado construido por el traductor de los cuentos se une con los del ilustrador y del adulto lector para marcar la recepción del texto por parte del niño.

Por medio de un análisis de las láminas que acompañan al relato desde su primera impresión española hasta el año 1975, nuestro objetivo es demostrar la importancia de los dibujos en la recepción del cuento en España y determinar 
en qué medida han tenido influencia en nuestra interpretación del cuento, así como en la percepción que tenemos de diversos aspectos del cuento.

\section{Las ilustraciones de "Caperucita Roja" en España}

Las ilustraciones de Antoine Clouzier que acompañan el cuento en su primera edición impresa dentro del volumen Histoires ou contes du temps passé de Perrault (1697), se caracterizan por su pobreza y escasa calidad, por lo que, desde muy temprano, las ediciones posteriores las fueron cambiando. En las versiones españolas ni siquiera se utilizaron. Para nuestro estudio, hemos manejado 24 ejemplares en español de los cuentos de Perrault que incluyen el cuento de "Caperucita Roja". Cubren un período de más o menos 150 años: de 1824, año de la primera traducción al español (PERRAULT, 1824), hasta 1975, el final del régimen franquista. Sin contar la primera impresión que no incluye ninguna ilustración (PERRAULT, 1824), podemos distinguir dos grupos en el tiempo. Un primer período, que va desde 1851 hasta 1892, agrupa a nueve textos (PERRAULT, 1851, 1852, 1862b, 1863, 1867, 1872, 1883a, 1883b, $1884,1892)$. Dos de estos nueve volúmenes no cuentan con ilustraciones (PERRAULT, 1872, 1892), otros dos contienen algunas imágenes, pero no de Caperucita Roja (PERRAULT, 1851, 1852, 1862b). Así, podemos afirmar que solo en la mitad de las traducciones editadas en el siglo XIX el cuento de la niña y el lobo se acompańa de imágenes.

Después de un silencio editorial de casi treinta ańos, en 1920 empieza un nuevo período en el que prosperan las reimpresiones de Perrault en Espańa: de 1920 a 1975 hemos encontrado catorce ediciones (PERRAULT, 1920, 1930, 1933, 1936, 1941a, 1941b, 1941c, 1941d, 1947, 1952, 1958, 1959, 1960, 1973). De ellas, solo dos volúmenes no contienen ilustraciones para nuestro cuento (PERRAULT, 1952, 1959), clara señal de la importancia que van adquiriendo con el tiempo.

Solo hay dos autores que repiten en varias ediciones: los dibujos de Gustave Doré, decisivos en nuestra percepción del texto - como veremos más adelant e-, vieron por primera vez la luz en 1862 en una tirada en francés a cargo de Jules Hetzel en las prensas parisinas de Jules Claye (PERRAULT, 1862a). Los 41 grabados que acompañaron los diez cuentos corrieron a cargo de los más célebres grabadores del momento, destacando sobre todo Pizan y Pannemaker. El éxito de este trabajo llevó a la imprenta a realizar un año después, en 1863, 
una composición en español, que utilizó una selección de estos dibujos de Doré (PERRAULT, 1863). Esta se hizo a cargo de Abel Ledoux, siendo el traductor Federico de la Vega. Las ediciones de 1883 (PERRAULT, 1883a) y de 1973 (PERRAULT, 1973) retoman las láminas de Doré. Las vińetas de G. Staal, por su parte, se disponen en dos traducciones distintas de la Librería Garnier en París: una primera vez en 1867 y una segunda en 1884 (PERRAULT, 1867, 1884). En esta última se añaden otras composiciones de nuevos ilustradores.

Alvstad (2010) indica tres razones por las que se explican tales modificaciones. En primer lugar, las nuevas ilustraciones suponen una renovación del relato. En segundo lugar, puede interpretarse como una "domesticación cultural" del texto, de modo que el libro no parezca una traducción y se adapte mejor a la nueva cultura, sobre todo si se contrata a ilustradores conocidos en ese nuevo territorio. Por último, cambiar las imágenes también puede modificar el contenido de un libro.

No todas estas razones tienen el mismo valor en las versiones de "Caperucita Roja". Es verdad que niños están poco interesados en el valor histórico de un cuento o un libro, en primer lugar quieren leer o escuchar una historia que les gusta o llama la atención. En ese sentido se observa claramente que las ediciones modernas que recogen las ilustraciones de Doré ${ }^{1}$ se dirigen más bien a un público adulto amante de libros antiguos que a unos lectores infantiles. Por el contrario, las ediciones para nińos recogen dibujos que son reflejos de las respectivas modas en la ilustración literaria de cada momento.

En cuanto a la domesticación cultural, sin embargo, los cuentos de hadas son un caso especial. Por mucho que Perrault sea un autor francés del siglo XVII, los cuentos se suelen considerar como un patrimonio universal que no pertenece a ninguna nación en concreto. Es más, una de las características de los cuentos de hadas es que se suelen situar en tiempos y lugares remotos. Las ilustraciones suelen acentuar este carácter exótico, mostrando castillos medievales, princesas con ropajes antiguos... A veces, incluso, se utiliza un lenguaje icónico que hace referencia a culturas orientales.

A continuación, pondremos ampliamente de relieve, con la aportación de ejemplos concretos, que las ilustraciones también pueden manipular el contenido originario, tal como afirma Alvstad, porque, aunque inconscientemente, nuestra interpretación y consecutiva recepción de ciertos pasajes, o incluso del cuento entero, se ve afectado por las imágenes que lo acompañan. 


\section{La edad de Caperucita}

Las ilustraciones muestran el aspecto visual de los personajes, completando así su caracterización. En el caso de "Caperucita Roja", una de las primeras cuestiones que tiene que determinar un ilustrador es la edad que va a tener la protagonista, y más cuando las indicaciones que da el autor son un tanto ambiguas. En la primera frase habla de une petite fille (PERRAULT, 1989, p. 258), "una chica pequeña", y en la moraleja de jeunes enfants, surtout de jeunes filles (PERRAULT, 1989, p. 260): "niños jóvenes, sobre todo niñas jóvenes". Pero la situación se complica si seguimos leyendo la moraleja, ya que en ella Perrault deja claro que hay que interpretar el cuento en un sentido sexual: de pronto ya no dirige su advertencia sobre los lobos, sino sobre toute sorte de gens ("todo tipo de gente"). Acto seguido, vuelve a referirse a los lobos, pero ahora indica que los dulzones, los más peligrosos de todos, Suivent les jeunes Demoiselles I Jusque dans les maisons, jusque dans les ruelles ${ }^{2}$ (PERRAULT, 1989, p. 260) con la intención de comérselas, es decir, que iya no habla de niñas infantiles sino de "jóvenes señoritas"!

Si la imagen generalizada que tenemos de Caperucita Roja es de una niña pequeña, esto puede justificarse, entre otras causas, debido a que la explicación sexual se ha perdido con el tiempo y porque automáticamente aplicamos la edad del público lector a la edad del protagonista. No podemos olvidar, sin embargo, que Perrault escribió solo en apariencia para niños; en realidad, sus textos se destinaban al público adulto de los salones parisinos de su tiempo ${ }^{3}$. Además, tampoco podemos pasar por alto el hecho de que todas las demás protagonistas femeninas de los cuentos de Perrault son adolescentes en la edad de casarse: las dos hermanas de "Las Hadas", "Cenicienta", la joven mujer de "Barba Azul" y las princesas de "La Bella Durmiente del Bosque", "Riquete el del Copete" y "Piel de Asno".

Sin duda, un factor decisivo para nuestra percepción colectiva de Caperucita como niña, ha sido el hecho de que aparece como tal en la inmensa mayoría de las ilustraciones, desde las primeras ediciones hasta hoy. Considerando la tesis de Pereira (2008) de que la imagen de un personaje visto por un determinado ilustrador puede llegar a ser tan poderoso que se convierte en un estereotipo de la obra en el sistema literario, podemos afirmar que este ha sido el caso de la Caperucita de Doré. El ilustrador francés nos muestra una niña con gorrito, bollo y bote de manteca que no puede superar los cinco años 
-una edad más bien temprana para ir sola cruzando un bosque - y que indica el camino a un lobo bastante más grande que ella (imagen 1).

Imagen 1 - Ilustración de G. Doré

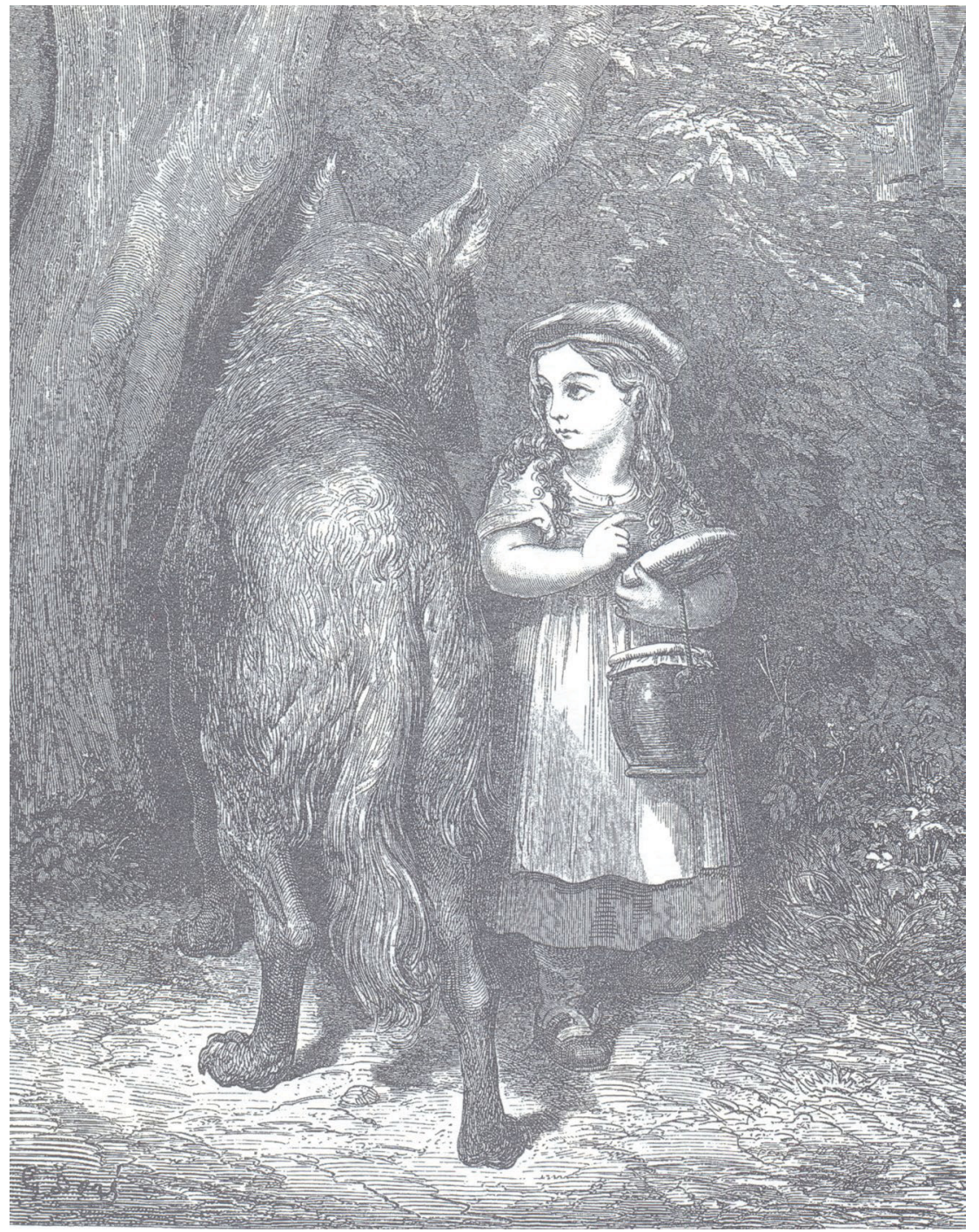

Fonte: Edición de Jules Hetzel (PERRAULT, 1862a); Abel Ledoux (PERRAULT, 1863); Luis Tasso y Serra (PERRAULT, 1883a); La Gaya Ciencia (PERRAULT, 1973). 
Esta imagen icónica ha marcado el camino para casi todos los ilustradores posteriores. Solo encontramos una edición, de 1867, cinco años después de que Doré realizara sus dibujos, que muestra a Caperucita como adolescente: la viñeta de G. Staal realizada para la Librería de Garnier Hermanos (imagen 2) (PERRAULT, 1867). No obstante, cuando la misma editorial pone en 1884 en el mercado una nueva traducción del cuento combinando los dibujos de Staal de la anterior edición con otros nuevos de Yan D'Argent, Tofani, etcétera, nos encontramos con la extraña situación de que en un mismo volumen se combinan ilustraciones de una Caperucita adolescente con una niña que parece inspirada en la de Doré (PERRAULT, 1884) (imágenes 2 y 3).

Imagen 2 - Ilustración de G. Staal

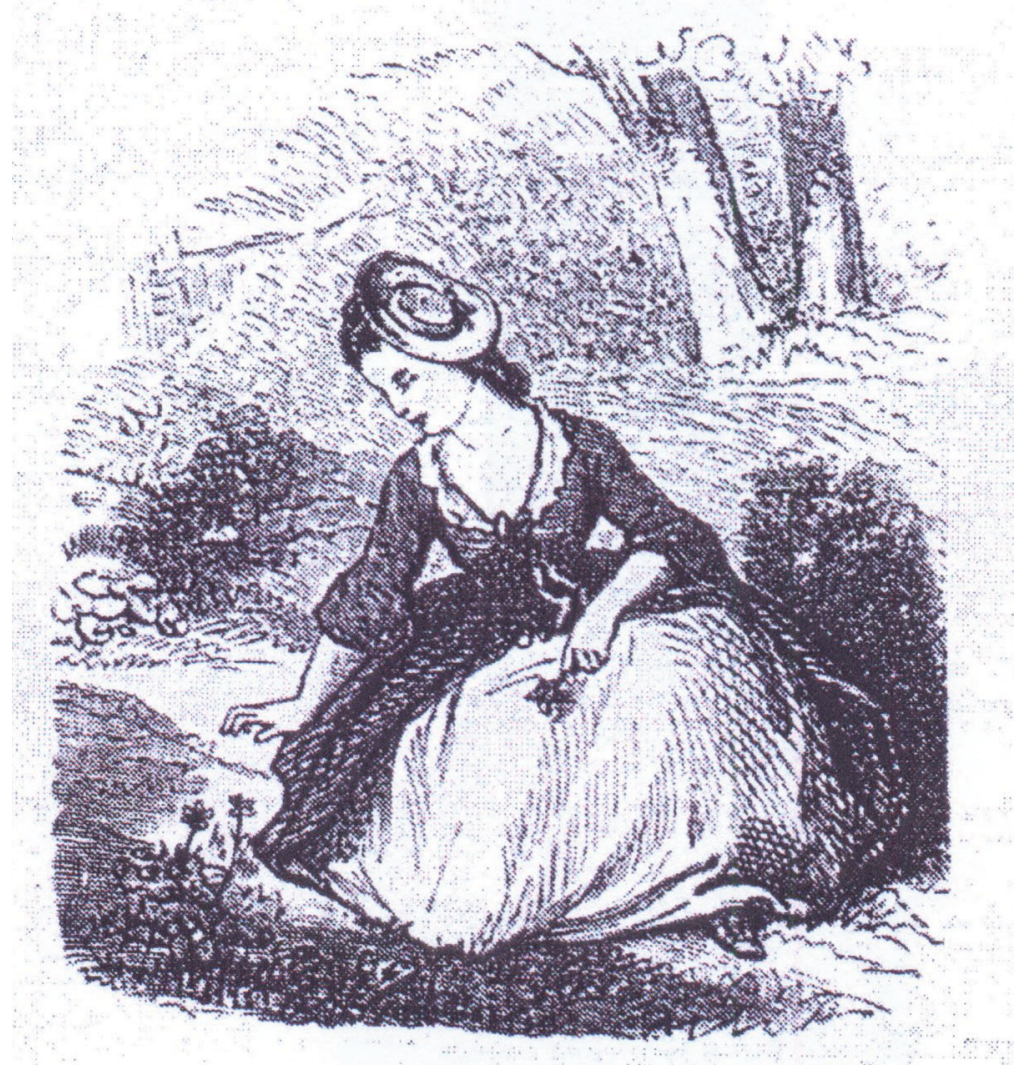

Fonte: Edición de Garnier Hermanos (PERRAULT, 1867, 1884). 


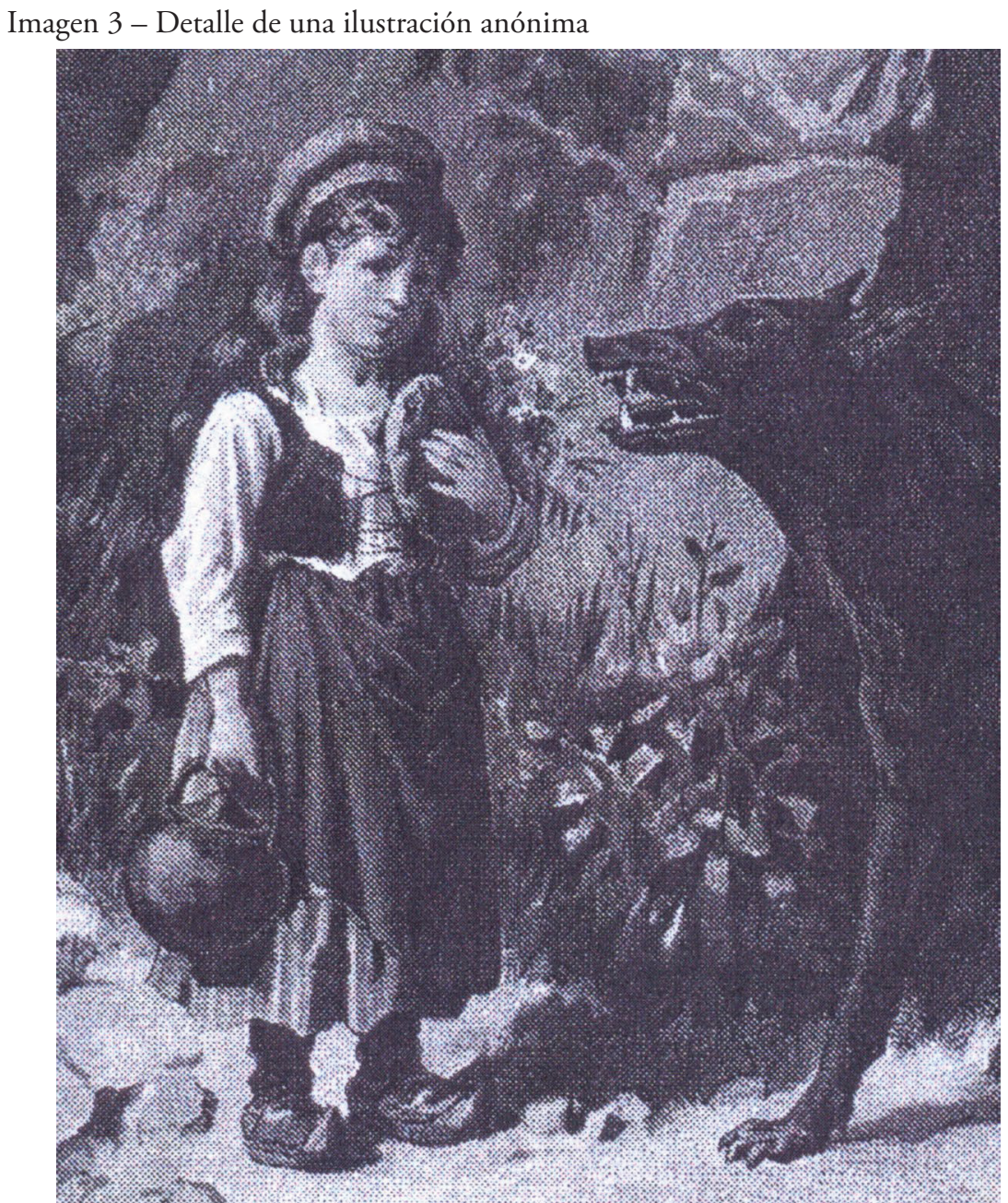

Fonte: Edición de Garnier Hermanos (PERRAULT, 1884).

\section{La ropa del lobo}

En ocasiones, las imágenes añaden elementos que no se mencionan en el texto. Así, Perrault no comenta que el lobo se hubiese puesto la cofia y/o las gafas de la abuela. Es más, cuando Caperucita se mete en la cama con él, el autor escribe: elle fut bien étonnée de voir comment sa Mère-grand était faite 
en son déshabillé (PERRAULT, 1989, p. 259) . Por lo tanto, supuestamente el lobo no llevaba nada de ropa interior ni complementos.

Sin embargo, de los nueve volúmenes que proporcionan una imagen del lobo en la cama de la abuela, solo hay dos que no le incluyen ningún atributo5; los demás lo visten, al menos, con una cofia. Hay que apuntar que posiblemente también influye una contaminación con la versión de los hermanos Grimm del cuento de Caperucita Roja, ya que en ese texto sí que se menciona que el lobo se adorne con la ropa y el gorro de la abuela antes de entrar en la cama para esperar a la niña 6 .

Como viene siendo habitual, Doré es el primero en marcar esta tendencia, aunque él se limita a incluir una cofia al lobo (imagen 4).

Imagen 4 - Ilustración de G. Doré

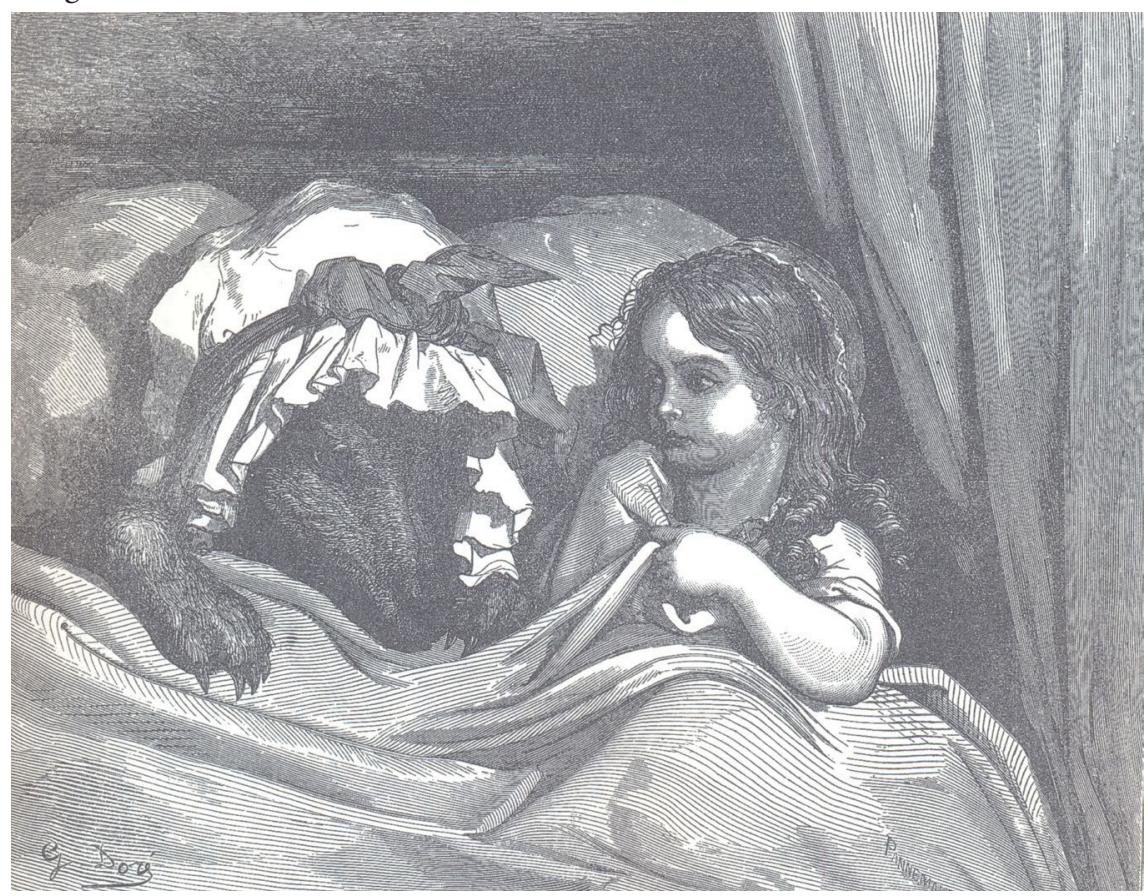

Fonte: Edición de Jules Hetzel (PERRAULT, 1862a); Abel Ledoux (PERRAULT, 1863); Luis Tasso y Serra (PERRAULT, 1883a). 
Las gafas tan solo aparecen en los dibujos de Doré en la escena anterior, en la que el lobo ataca a la abuela: muestra cómo sus gafas caen al suelo a causa de la violencia utilizada por el animal (PERRAULT, 1862a, 1863, 1883a, 1973) (imagen 9). A partir de las imágenes realizadas por Penagos para la editorial Saturnino Calleja en 1920, todas las ilustraciones que presentan al lobo con gorro, también le incluyen gafas (imagen 5) (PERRAULT, 1920).

Imagen 5 - Ilustración de R. de Penagos

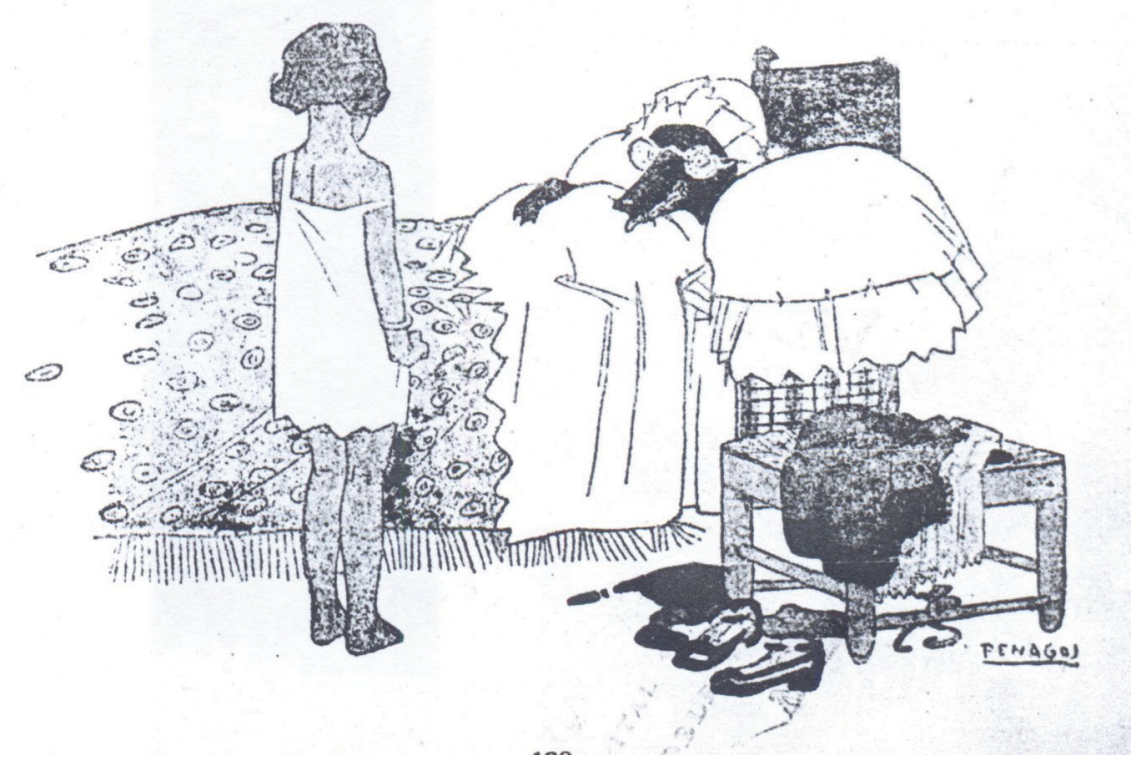

Fonte: Edición de Saturnino Calleja (PERRAULT, 1920).

Que el lobo lleve una cofia y unas gafas, en sentido estricto, no entra en conflicto con la descripción del lobo desnudo que nos proporciona Perrault. No obstante, encontramos dos ediciones que lo representan, además, con un camisón, contradiciendo así el texto original. Se trata de las ilustraciones de Jaime Juez (PERRAULT, 1958) (imagen 6) y de las de Lafitte (PERRAULT, 1960) (imagen 11). 
Imagen 6 - Ilustración de Jaime Juez

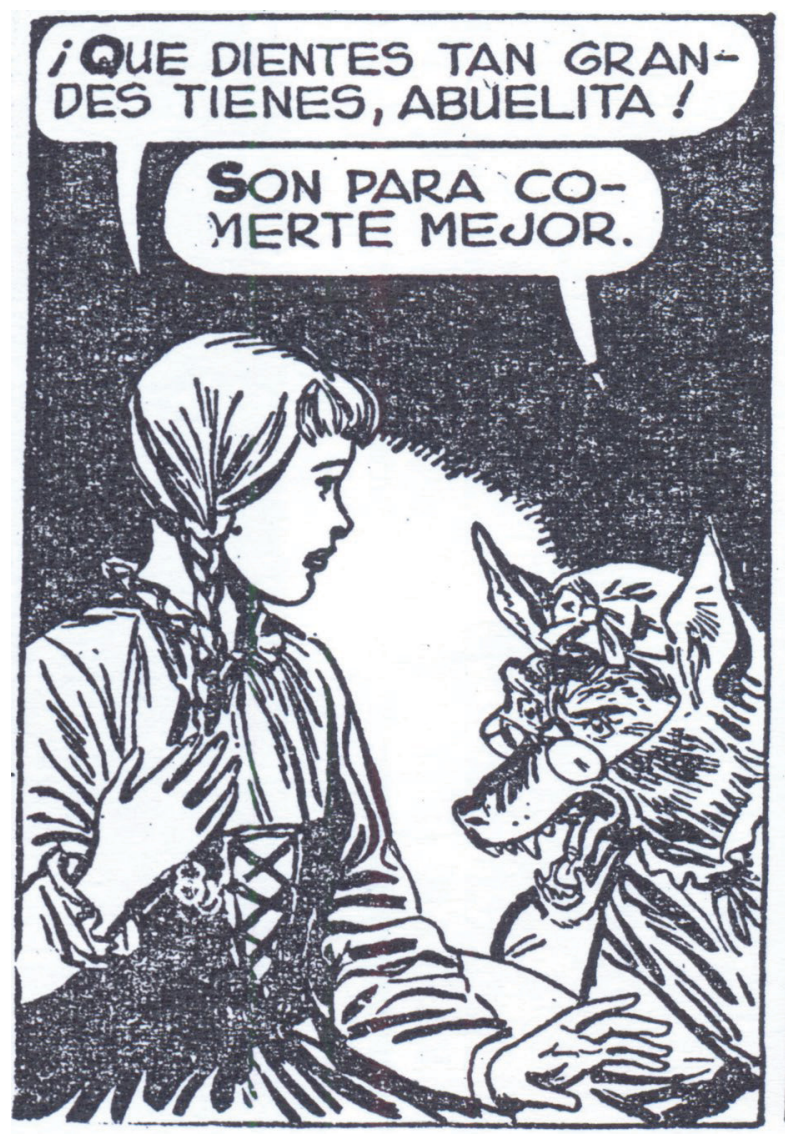

Fonte: Editorial Bruguera (PERRAULT, 1958).

Oittinen (2006) y O'Sullivan (2006) indican que, de manera consciente o involuntaria, las ilustraciones dejan a modo de "interilustratividad" su huella en el traductor, quien, como cualquier lector, crea un significado en su mente combinando lo textual y lo visual. En casos extremos, el traductor puede decidir alejarse del texto original para adaptarse mejor a las representaciones pictóricas. Es evidente que este proceso solo puede llegar a buen fin si el traductor sabe cuáles van a ser las ilustraciones que acompañan su texto. Así, vemos que algunos traductores intentan justificar la vestimenta del lobo presente en las imágenes. 
El primero en hacer esto es el traductor anónimo de la edición de Saturnino Calleja de 1941 (PERRAULT, 1941b). Ya que se muestra al animal con gorro y gafas, el texto explica como sigue: "Buscó en la cómoda ropa que ponerse, y luego de calarse las gafas de la abuela, que estaban en la mesa de noche, se metió en la cama" (PERRAULT, 1941b, p. 174). Cuando un poco más tarde Caperucita se sorprende al ver las grandes orejas del lobo, la traducción ańade: "En efecto, al lobo se le salían las orejas de la cofia, no muy bien encajada. Detrás de las gafas, sus ojos relucían de ansia" (PERRAULT, 1941b, p. 175). Lo curioso es que unos años más tarde, en 1947, otro traductor, Federico Torres (PERRAULT, 1947), se inspira en la versión de su compañero de 1941 y la repite de manera muy parecida, aunque esta edición no contiene ninguna imagen del lobo en la cama. El cambio en una traducción inspirada por las ilustraciones se mantiene, por tanto, incluso al desaparecer las imágenes que lo han provocado 7 .

\section{¿Valores cristianos?}

Perrault se opone a las epopeyas de la tradición clásica por considerarlas aburridas, además de amorales y llenas de creencias incomprensibles y paganas, argumentando que los cuentos narrados por los paisanos al lado de la lumbre son superiores por estar impregnados de una moral cristiana (SORIANO, 1989). En realidad, el origen de los cuentos de hadas europeos no tiene nada que ver con el cristianismo, pero el autor francés utiliza este argumento para defender a los "modernos" y enfrentarse así a autores como Boileau y Racine en la querelle des anciens et des modernes (debate de los antiguos y los modernos) (SORIANO, 1989). Si bien es verdad que Perrault se esfuerza por añadir a cada uno de sus cuentos una o incluso varias moralejas, hay que subrayar, sin embargo, que los textos apenas tienen referencias católicas o, en un sentido más amplio, religiosas. El cuento de "Caperucita Roja" se podría haber escrito perfectamente de la misma forma por un autor no cristiano.

En muchos países europeos, entre los que podemos incluir a España, ha habido períodos en los que se criticaban los cuentos de hadas por moverse en el terreno de la fantasía y no enseñar bastantes conocimientos útiles a la juventud. Para anticipar posibles críticas, algunos editores han decidido enfatizar la respetable moral de los cuentos introduciendo sutilmente algunas referencias cristianas. En el caso de Caperucita Roja, en concreto, encontramos 
dos ilustraciones que muestran símbolos religiosos. El primer ejemplo es una cruz colgada en la pared de la habitación de la abuela en la edición de 1930 de Dalmáu Carles (imagen 7).

Imagen 7 - Ilustración anónima

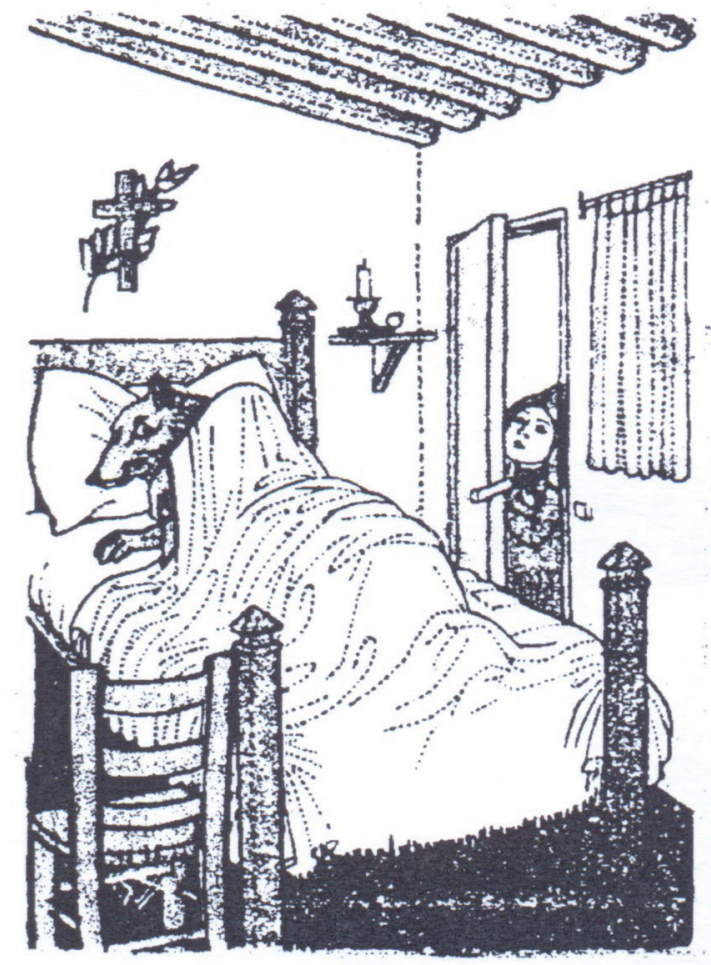

Fonte: Edición de Dalmáu Carles, Pla (PERRAULT, 1930).

El segundo ejemplo es una ilustración de la mano de Penagos para la editorial Saturnino Calleja (PERRAULT, 1941b). El dibujo es muy parecido al que el ilustrador realizó en 1920 para la misma editorial (imagen 5) (PERRAULT, 1920), pero se ańade un retrato de la virgen en la pared encima de la cama (imagen 8). Sin duda, esta alteración es fruto del contexto histórico en el que emergen: mientras que la primera edición se publicó bajo el reinado de Alfonso XIII, la segunda vio la luz en los años más duros del régimen franquista, que tenía el Nacionalcatolicismo como una de las señas de su identidad ideológica. 
Imagen 8 - Ilustración de R. de Penagos

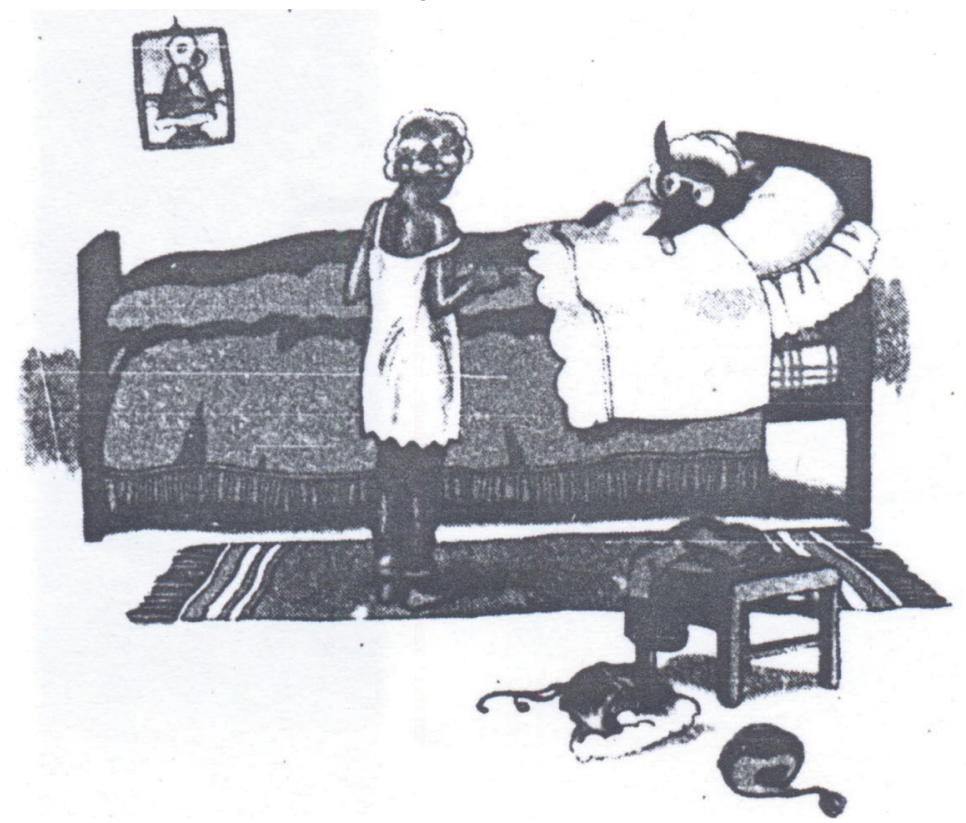

Fonte: Edición de Saturnino Calleja (PERRAULT, 1941b).

\section{Proteger a la juventud y guardar la moral}

El mero hecho de incluir algún símbolo religioso en las ilustraciones evidentemente no basta para que una obra se considere apta para un público infantil. Todo el contenido tiene que cumplir con las normas morales vigentes en una determinada época. No solo se trata de enseñar de manera explícita la moral correcta-objetivo que se cumple gracias a la moraleja-, sino que también hay que proteger al niño de contenidos susceptibles de generarles demasiado temor o de posibles malas influencias ocultas en la obra.

El cuento de "Caperucita" en la versión de Perrault (1697) tiene un carácter particularmente violento ya que termina con la muerte de la abuela y su nieta, sin que acuda ningún cazador a salvarlas, final feliz que añadirán en su versión los hermanos Grimm. Algunas traducciones intentan suavizar este cruel cierre cambiándolo o ańadiendo una segunda versión. Los ilustradores, sin embargo, utilizan sus propios recursos para solucionar el conflicto: si las 
ilustraciones de un cuento se suelen concentrar en las escenas más importantes de la historia, lo lógico sería que las ediciones mostraran al lobo primero devorando a la abuela y luego a Caperucita. Constatamos, sin embargo, que los ilustradores evitan recrear esos pasajes. De todas las ediciones analizadas, solamente encontramos a tres ilustradores que muestran el ataque del lobo a la abuela: Gustave Doré (PERRAULT, 1862a, 1863, 1883a, 1973) (imagen 9), el ilustrador anónimo que embellece la traducción de Cecilio Navarro de 1941 (PERRAULT, 1941a) y el autor de las imágenes que acompañan a la traducción de Pedro Pedraza y Páez en el mismo año (PERRAULT, 1941c). Los tres dibujos se centran en el momento en el que el lobo salta encima de la cama, asustando a la pobre vieja. Sin embargo, el clímax absoluto del cuento, cuando el lobo termina devorando a la nińa, no aparece representado en ninguna edición. La única excepción es quizá el principio del ataque del lobo en la ilustración realizada por Lafitte para acompañar a la traducción de Federico Torres de 1960 (PERRAULT, 1960) (imagen 11). Evidentemente, se prefiere dibujar a Caperucita cogiendo flores por el bosque, aunque esto sea un simple detalle en la narración.

Otro pasaje problemático del cuento para traductores e ilustradores es el momento en el que el lobo le pide a Caperucita que se acueste con él. Perrault escribe Le petit chaperon rouge se déshabille, et va se mettre dans le lit ${ }^{8}$ (PERRAULT, 1898 , p. 259). A la luz de las claras intenciones de Perrault de sugerir una interpretación en el sentido sexual, como indicamos antes, no podemos hacer otra cosa que reconocer que la nińa accede voluntariamente al acto sexual: el lobo solo le había pedido que se acostara con él, no que se desnudara. Está claro que los ilustradores tienen que buscar una solución para este problema.

El primer aspecto a tener en cuenta en este sentido, ya tratado con anterioridad, es la presentación de Caperucita como una niña pequeña. En segundo lugar, hay que mencionar que no hay ninguna ilustración que muestre a una nińa desnuda tal cual. Obviamente, vuelve a haber una parte considerable de las traducciones que evita representar la escena, aunque menos que en el caso del ataque del lobo. En el siglo XIX, encontramos dos ilustraciones del pasaje en cuestión, ambas con una Caperucita que se encuentra en la cama al lado del lobo, tapándose con las sábanas. Se trata de Doré (imagen 4) (PERRAULT, 1862a, 1863, 1883a) y la edición de 1883 ilustrada por Vicente Urrabieta y Julian Bastinos (PERRAULT, 1883b). En ambos casos parece que la niña lleva puesto un camisón. 
Imagen 9 - Ilustración de G. Doré

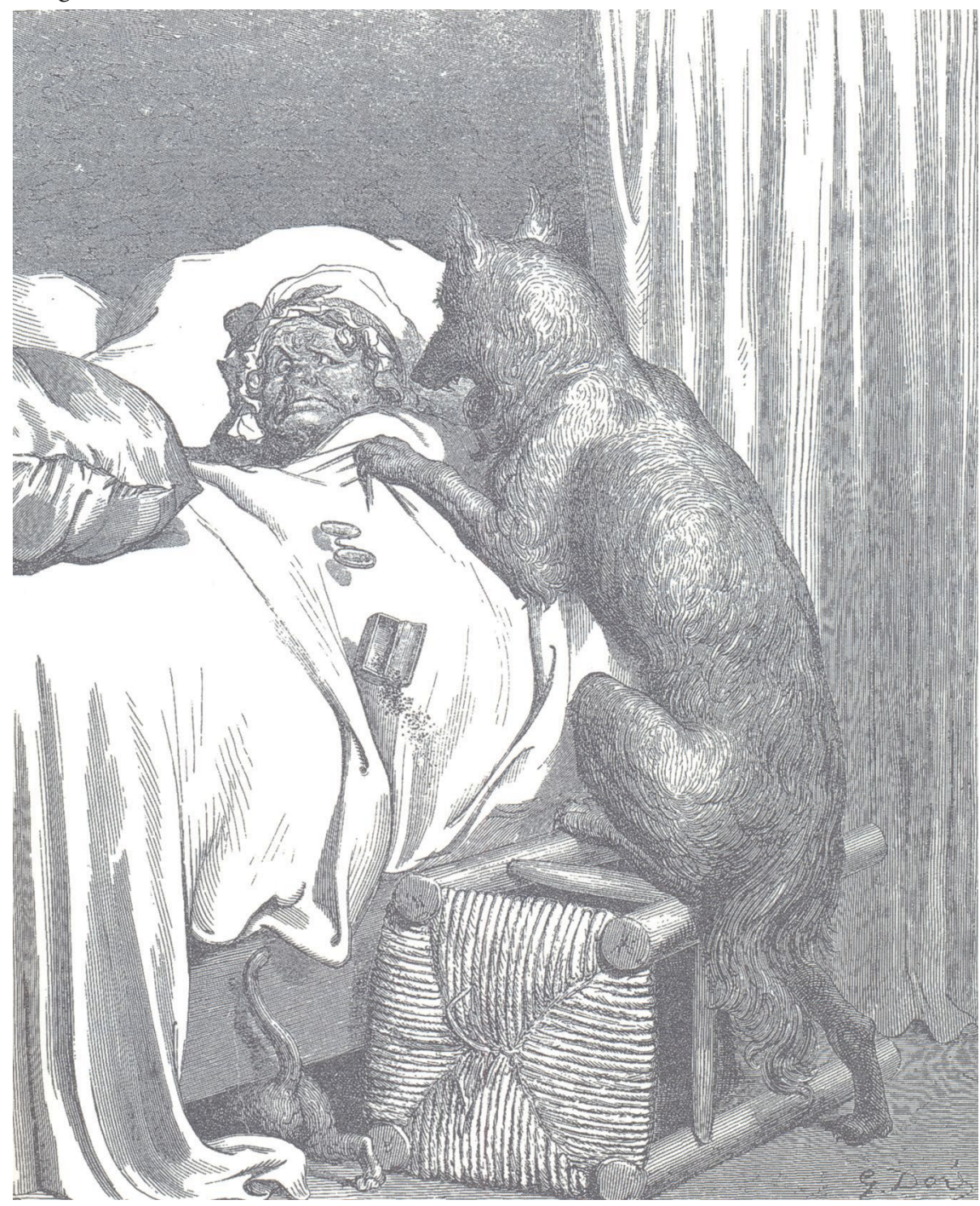

Fonte: Edición de Jules Hetzel (PERRAULT, 1862a); Abel Ledoux (PERRAULT, 1863); Luis Tasso y Serra (PERRAULT, 1883a); La Gaya Ciencia (PERRAULT, 1973).

En el siglo XX la nińa ya no aparece en la cama con el lobo, ni siquiera en la edición de La Gaya Ciencia que recoge la gran mayoría de las ilustraciones 
de Doré (PERRAULT, 1973): suele estar al lado, mirando al animal. En tres ediciones se ha quitado la ropa, pero todavía lleva un camisón. Llama la atención que siempre la vemos de espalda. Se trata de los dibujos de Penagos para las ediciones de Saturnino Calleja de 1920 (imagen 5) (PERRAULT, 1920) y 1941 (imagen 8) (PERRAULT, 1941b), y de las imágenes que acompañan la traducción de Pedro Pedraza y Páez de ese mismo año (PERRAULT, 1941c). En otras tantas ediciones vemos que la niña no se quita la ropa, lo que lleva a un conflicto entre el texto y las imágenes. Es el caso de las ilustraciones realizadas por Manuela de Velasco (PERRAULT, 1933) (imagen 10) y de Jaime Juez (PERRAULT, 1958) (imagen 6).

Imagen 10 - Ilustración de Manuela de Velasco

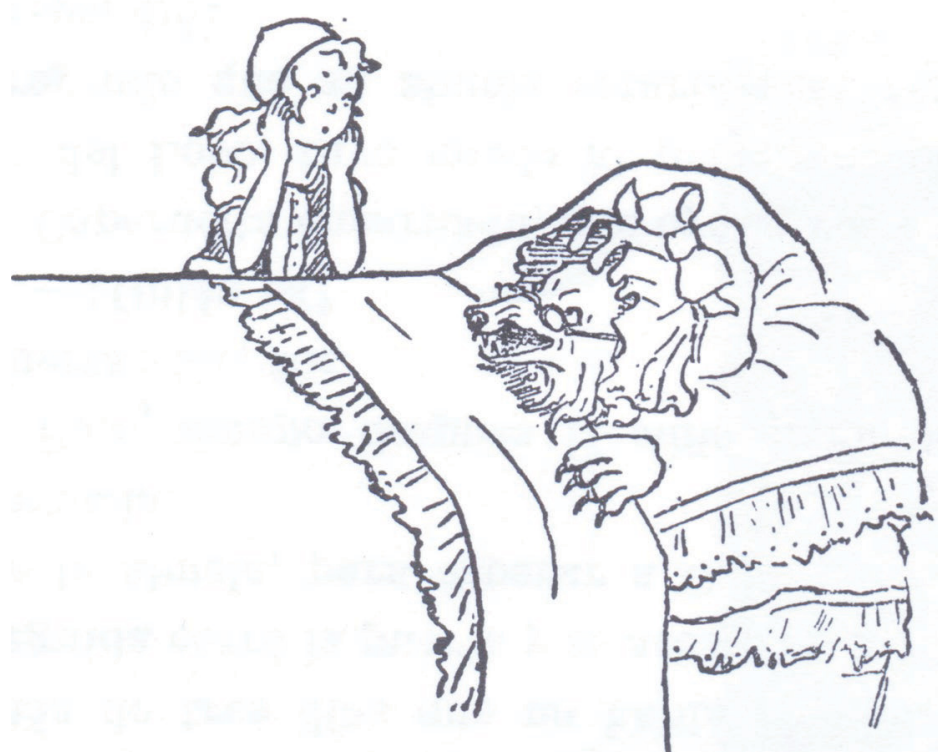

Fonte: Edición de Espasa-Calpe (PERRAULT, 1933).

En una última edición (PERRAULT, 1960) se intenta evitar la diferencia entre el texto y los dibujos, por lo que se adapta la traducción, pero esto solo se consigue en parte. La imagen de Lafitte muestra a una nińa vestida al lado de la cama en el momento en el que el lobo se la quiere comer (imagen 11). La traducción de Federico Torres, en efecto, elimina el hecho de que Caperucita se desnude. Deja bien claro, sin embargo, que la nińa se mete en la cama, lo 
que no apreciamos en el dibujo: "Ven a acostarte conmigo, que tengo mucho frío. Caperucita, como era muy obediente, sin rechistar se dispuso a cumplir la orden" (PERRAULT, 1960, p. 54).

Imagen 11 - Ilustración de Lafitte

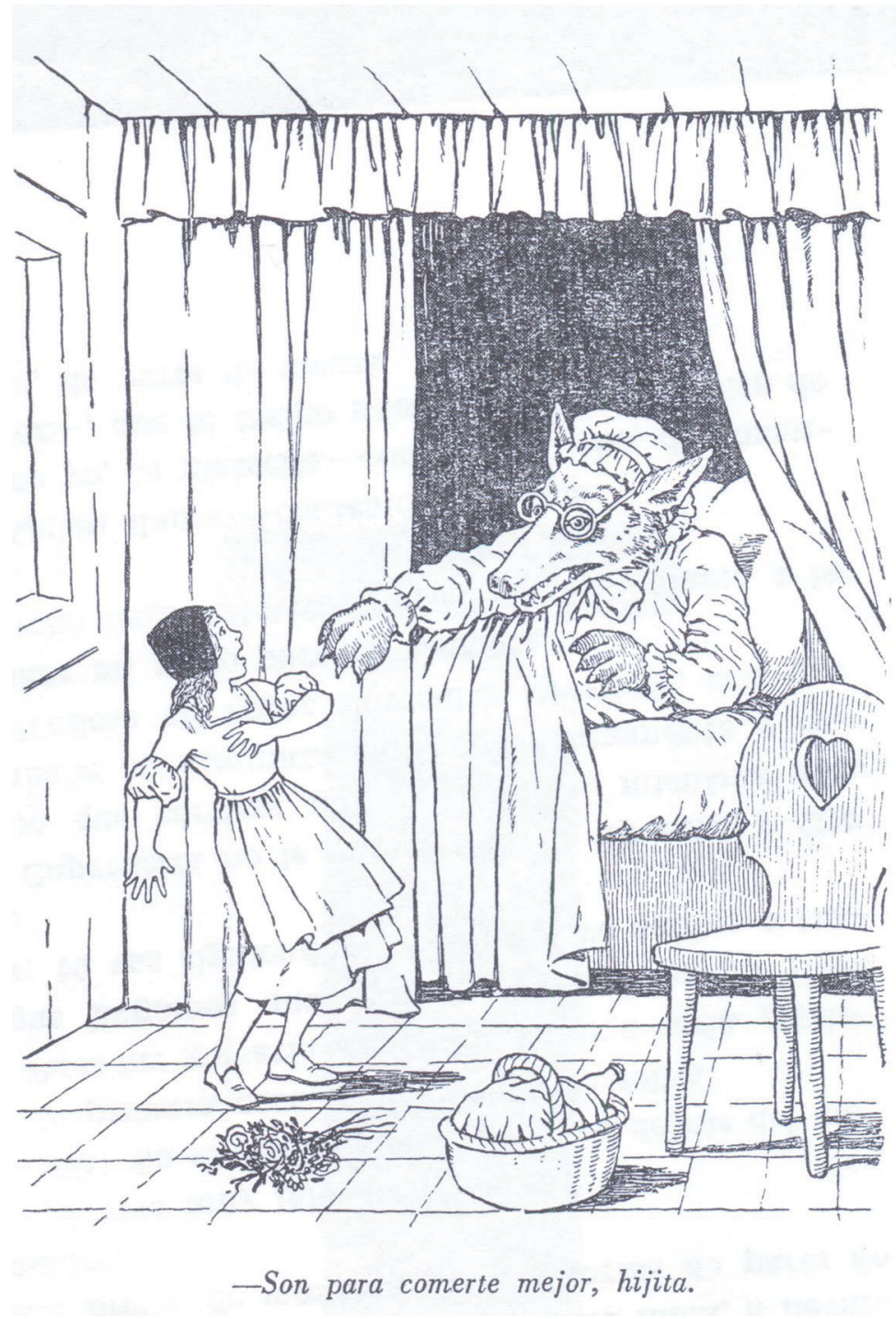

Fonte: Edición de Gráficas Yagües (PERRAULT, 1960). 
Es evidente que tales incongruencias entre las imágenes y el texto tienen que causar cierto desconcierto entre los jóvenes destinatarios del cuento. Teresa Colomer (2005) nos enseña que la reacción de los niños frente a problemas de este tipo depende de su edad. Cita a Michael Chandler, quien expuso el caso de una ilustración de un niño sonriente cuando le estaban poniendo una inyección. Mientras que los niños de más de seis años intentan explicar la situación buscando una solución creativa -el niño y su padre estaban jugando a ser médicos- los de menor edad pasan por alto el dibujo e insisten en que el niño estaba asustado.

\section{Conclusiones}

Nuestro análisis de diecisiete traducciones españolas ilustradas del cuento de "Caperucita Roja" pone de relieve que el significado de un texto se establece por la conexión en nuestra mente de las palabras y el aspecto visual. Aunque el cuento no necesita obligatoriamente la ayuda de ilustraciones para sobrevivir como clásico de la literatura universal dirigido a un público infantil, prueba de lo cual son las siete ediciones que no incluyen dibujos, la eventual presencia de las ilustraciones condiciona la recepción y la interpretación del relato.

Las imágenes completan las caracterizaciones de los personajes, eliminando cierta ambigüedad del texto original. Determinados elementos del texto son acentuados en detrimento de otros y se añaden detalles aparentemente insignificantes para dirigir la interpretación en una u otra dirección, promover una ideología que no necesariamente estaba presente en el texto original o adaptar el cuento a las exigencias educativas y/o morales de la cultura meta. En ocasiones, esto provoca conflictos e incongruencias entre lo verbal y lo visual que incluso pueden desembocar en modificaciones duraderas de las traducciones.

Las imágenes, en definitiva, son mucho más que meras ilustraciones de un texto canónico, pues a menudo los lectores no llegan a percatarse de la importancia de esas ilustraciones que, por un lado, pueden manipular el contenido de la obra original, en este caso un clásico de la literatura infantil y juvenil, y, por otro, llegar a condicionar su manera de interpretarla y asimilarla. 


\section{Notas}

1 En la actualidad se siguen editando ediciones facsímiles de la primera traducción española con las ilustraciones de Doré.

2 "Siguen a las jóvenes señoritas / Hasta en las casas, hasta en los callejones" (traducción propia). Sobre la interpretación sexual del cuento de Caperucita Roja: BETTELHEIM, 1999.

3 Uno de los primeros autores en indicar que el público para el que Perrault redactó sus cuentos eran adultos, fue Percy Muir (1954). Si bien reconoce que los cuentos de hadas habían sido contados a los niños antes de dormir durante muchos siglos, enfatiza que a finales del siglo XVII se produjo un cambio y se pusieron de moda entre los adultos que asistían a los salones literarios en el París de Luis XIV. Este cambio de público deja su huella en la forma que toman los relatos de Perrault y sus contemporáneos (MUIR, 1954). Zohar Shavit (1986) es sin duda quien más ha profundizado en la cuestión del receptor de los cuentos de Perrault. La autora establece el concepto del doble destinatario de los cuentos de hadas en la época de Perrault: si en realidad los cuentos se escribieron para los adultos de las clases altas y no cabe duda de que fueron estos sus principales o incluso únicos lectores en ese momento, las convenciones sociales y literarias dictaron que oficialmente se dirigieran a los niños y a las clases bajas. Estas circunstancias particulares permitieron a los autores jugar sutilmente con los contrastes entre unos cuentos ancestrales para niños y para el pueblo llano y los guiños a una sociedad altamente refinada: "Therefore the reading of fairy tales by highbrows was based on a silent agreement (between them and the writer) about two implied readers - the child and the highbrow adult- and on a tacit agreement on the writer's intentions, leaving much room for the writer to play between them" (SHAVIT, 1986, p. 9). Solo varias décadas más tarde, cuando el contexto histórico y social cambió definitivamente, los niños volvieron a apropiarse de los cuentos. Es en ese momento cuando empiezan a destacar los cuentos de Perrault por encima de los de sus contemporáneos. Mientras que la mayor parte de los cuentos redactados a finales del siglo XVII y principios del siglo XVIII resultaban demasiado complicados y sofisticados para los niños, los de nuestro autor, que había buscado imitar la sencillez de las narraciones populares que formaban la base de su material, fueron del agrado del público infantil. En este sentido, 
Zuber afirma: "La présence d'un public enfantin est la condition même de l'émergence du conte de fées. Perrault a compris cette condition, et il a donc écrit ses Contes comme si des enfants étaient en train de l'écouter" (ZUBER, 1992, p. 186-187, cursiva en original). Lathey añade: "Perrault produced a collection of polished stories with straightforward plots, shorter than those of d'Aulnoy and better suited to a young audience. [...] Perrault's tales retain qualities of the nursery story in their simplicity and repetition, but were not primarily addressed to young children" (LATHEY, 2010, p. 52).

4 "Se sorprendió al ver cómo era su abuela desnuda" (traducción propia).

5 Se trata de las imágenes que acompañan las traducciones de Maria Pla Dalmáu de 1930 (PERRAULT, 1930) y de Pedro Pedraza y Páez de 1941 (PERRAULT, 1941c).

6 La influencia de la versión de Grimm también la encontramos en los dibujos de M. Sierra (PERRAULT, 1947): mientras que, según Perrault, Caperucita solo debería llevarle un bollo y un bote de manteca a su abuela, se distingue una botella de vino en la cesta de la niña, lo que coincide con la versión alemana del cuento.

7 El mismo traductor, Federico Torres, volverá a hacer una nueva traducción para otra editorial en 1960. Aunque se trata de una adaptación del texto claramente distinta de la anterior traducción, Torres guarda la parte que justifica la ropa del lobo. En este caso, el texto se completa con ilustraciones de Lafitte que muestran a un lobo con camisón, gorro y gafas (PERRAULT, 1960).

8 "Caperucita Roja se desnuda y se mete en la cama" (traducción propia).

\section{REFERENCIAS}

ALVSTAD, Cecilia. Children's Literature and Translation. In: GAMBIER, Yves; VAN DOORSLAER, Luc (Ed.). Handbook of Translation Studies. 1. ed. Amsterdam: John Benjamins Publishing Company, 2010. 1 v. p. 22-27.

BALL VARGAS, Manuela S.; GUTIÉRREZ, María E. Estética de la recepción: cuando los niños pequeños aún no leen. Educere, Mérida, VE, v. 12, n. 42, p. 439-445, 2008. 
BETTELHEIM, Bruno. Psicoanálisis de los cuentos de hadas. Barcelona: Crítica, 1999.

COLOMER, Teresa. Andar entre libros: la lectura literaria en la escuela. México: FCE, 2005.

ISER, Wolfgang. El acto de leer. Madrid: Taurus Ediciones, 1987.

JAUSS, Hans Robert. Experiencia estética y hermenéutica literaria: ensayos en el campo de la experiencia estética. Madrid: Taurus Ediciones, 1986.

LATHEY, Gillian. The role of translators in children's literature: invisible storytellers. New York, Oxon: Taylor \& Francis, 2010.

MUIR, Percy. English Children's Books 1600-1900. 4. ed. London: Anchor Brendon, 1954.

OITTINEN, Riitta. The verbal and the visual: on the carnivalism and dialogics of translation for children. In: LATHEY, Gillian (Ed.). The translation of chidlren's literature: a reader. Toronto: Multilingual Matters, 2006. p. 84-97.

O'SULLIVAN, Emer. Translating Pictures. In: LATHEY, Gillian (Ed.). The translation of children's literature: a reader. Toronto: Multilingual Matters, 2006. p. 113-121.

PEREIRA, Nilce M. Book illustration as (intersemiotic) translation: pictures translating words. Meta, Montréal, v. 53, n. 1, p. 104-119, mar. 2008.

Disponible en: <http://id.erudit.org/iderudit/017977ar>. Acceso en: 20 feb. 2012.

PERRAULT, Charles. Histoires ou Contes du temps passé avec des moralitez. Illustrations d'Antoine Clouzier. Paris: Claude Barbin, 1697.

PERRAULT, Charles. Cuentos de las hadas. París: Imprenta de J. Smith, 1824.

PERRAULT, Charles. Cuentos de Carlos Perrault. Madrid: Imp. del Semanario Pintoresco, 1851-1852.

PERRAULT, Charles. Les contes de Perrault. Dessins par Gustave Doré. Paris: J. Hetzel, 1862a.

PERRAULT, Charles. Cuentos de hadas. Traducción de J. Coll y Vehí.

Barcelona: La Maravilla, 1862b. 
PERRAULT, Charles. Los cuentos de Perrault. Ilustrados por Gustavo Doré. Traducidos del francés por Federico de la Vega. Paris: Abel Ledoux, 1863.

PERRAULT, Charles. Cuentos de las hadas por Carlos Perrault, Ma Leprince de Beaumont, etc. Ilustraciones G. Staal. París: Librería de Garnier Hermanos, 1867.

PERRAUlT, Charles. Cuentos de las hadas por Ch. Perrault. Biblioteca de la Juventud. París: Librería de Rosa y Bouret, 1872.

PERRAULT, Claudio. Cuentos de Claudio Perrault y de Madama de Beaumont. Versión castellana de D. Cecilio Navarro. Ilustraciones de Gustavo Doré. Barcelona: Luis Tasso y Serra, 1883a.

PERRAULT, Charles. Cuentos de hadas por Carlos Perrault. Traducidos por D. Teodoro Baró. Ilustraciones de Vicente Urrabieta y Julián Bastinos. Barcelona: Librería de Juan y Antonio Bastinos, 1883b.

PERRAULT, Charles. Los cuentos de Perrault. Viñetas de G. Staal, Yan D’Argent, Tofani, et al. París: Librería de Garnier Hermanos, 1884.

PERRAULT, Charles. Cuentos de Perrault. Colección de los mejores autores antiguos y extranjeros. Tomo CXXXI. Madrid: Biblioteca Universal, 1892.

PERRAULT, Charles. Cuentos de Perrault. Ilustraciones de R. de Penagos. Madrid: Saturnino Calleja, 1920. (Primera serie. XXX).

PERRAULT, Charles. Cuentos de Perrault. Adaptación y versión españolas por D. Maria Pla Dalmáu. Gerona: Dalmáu Carles, Pla, S.A. - Editores, 1930.

PERRAULT, Charles. Algunos cuentos de Perrault. Ilustraciones de Manuela de Velasco. Madrid: Espasa-Calpe, 1933.

PERRAULT, Charles. Los mejores cuentos de Perrault. Mundo Infantil. Madrid: Lecturas para todos, 1936.

PERRAULT, Charles. Cuentos. Versión castellana de Cecilio Navarro. Ilustraciones de Gustavo Doré. Barcelona: Editorial Maucci, 1941a.

PERRAULT, Charles. Cuentos de Perrault. Ilustraciones de R. de Penagos. Madrid: Saturnino Calleja, 1941b. (Primera Serie. XXX).

PERRAULT, Charles. Cuentos de Perrault. Traducidos del francés por Pedro Pedraza y Páez. Ilustrados con 138 grabados. Barcelona: Editorial Ramón Sopena, 1941c. (Biblioteca para niños). 
PERRAULT, Charles. Cuentos de Perrault. Relatados a los niños por María Luz Morales. Con ilustraciones de Luis Álvarez. 4 ed. Barcelona: Editorial Araluce, 1941d.

PERRAULT, Charles. Cuentos infantiles. 2. ed. Adaptación de Federico Torres. Ilustraciones de M. Sierra. Madrid: Librería y Casa Editorial Hernando, 1947.

PERRAULT, Charles. Cuentos de hadas y otras narraciones. Traducción de María Teresa Vernet. Prólogo de Emiliano M. Aguilera. Obras Maestras. Barcelona: Editorial Iberia, S.A., 1952.

PERRAULT, Charles. Cuentos de Perrault. Adaptación de J. Alcántara Tarifa. Ilustraciones de Jaime Juez. Barcelona: Editorial Bruguera, 1958.

PERRAULT, Charles. Cuentos. Adaptación de J. Vendrell. Ilustraciones de Anita. Barcelona: Exclusivas Ferma, 1959. (Colección Gacela Blanca).

PERRAULT, Charles. Los mejores cuentos de Charles Perrault. Selección y adaptación de Federico Torres. Ilustraciones de Lafitte. Madrid: Gráficas Yagües, 1960.

PERRAULT, Charles. Cuentos de antaño. Traducción de Cecilio Navarro. Ilustraciones de Gustavo Doré. Diseño de la cubierta de Enric Satué. Barcelona: Editorial La Gaya Ciencia, 1973.

PERRAULT, Charles. Contes. Textes établis et présentés par Marc Soriano. Paris: GF-Flammarion, 1989.

SHAVIT, Zohar. Poetics of Children's Literature. Athens: The University of Georgia Press, 1986.

SORIANO, Marc. Introduction. In: PERRAULT, Charles. Contes. Textes établis et présentés par Marc Soriano. Paris: GF-Flammarion, 1989. p. 7-40.

ZUBER, Roger. Public d'enfants? Public d'adultes? Les Contes de Charles Perrault. In: FERRIER-CAVERIVIÈRE, Nicole (Éd.). Thèmes et genres littéraires aux XVIIe et XVIIIe siècles: mélanges en l'honneur de Jacques Truchet. Paris: Presses Universitaires de France, 1992. p. 185-187. 


\section{A Iguns problemas Some problems concerning relacionados com as illustrations in the ilustrações nas traduções translations of a classic of de uma obra clássica da children's literature: the Literatura Infantil e Juvenil: o case of "Little Red Riding caso da obra "Chapeuzinho Hood" in Spain Vermelho" na Espanha \\ Abstract}

\section{Resumo}

Em uma ediçấo ilustrada de uma obra literaria os elementos verbais combinamse e completam-se com o aspecto visual do volume para transmitir a mensagem ao leitor. Ao traduzir uma obra com essas características para outro idioma, procura-se, na medida do possível, respeitar o equilíbrio que se estabelece entre a informaçáo fornecida pelo texto e pelas imagens. Quando se trata de uma obra clássica que, no entanto, continua a ser editada ao longo de vários séculos, a situaçáo costuma ser bem mais complexa, já que, como é habitual, náo só se realizam novas traduçóes, mas também são modificadas as ilustraçóes. Iste é o caso das traduçôes espanholas do conto "Le Petit Chaperon Rouge" (Chapeuzinho Vermelho) de Perrault. As ilustraçóes tiveram uma importância fundamental na recepção da obra, contribuindo para a criação de um certo ambiente e completando a caracterizaçáo das personagens. Desta maneira, algumas ilustraçôes têm-se mostrado particularmente influentes, não apenas por terem influenciado os ilustradores das seguintes geraçôes, mas por introduzirem modificaçôes nas traduçōes do próprio

In an illustrated edition of a literary work, verbal elements combine with and are completed by visual aspects to convey their message to the reader. When translating the work into another language, we try, as far as possible, to respect the balance between the information provided in the text and in the images. When the work is a classic that has been republished over the ages, the situation is more complicated because usually not only the translations but also the illustrations are changed. This is the case of the Spanish translations of the story of "Le Petit Chaperon Rouge" (Little Red Riding Hood) by Perrault. The illustrations have had an undeniable importance in the reception of the work, creating a certain setting and completing the description of the characters. In this context, some illustrations have been particularly influential, not only leaving their mark on the illustrators of later generations, but also introducing changes in the translations of the story itself. Moreover, the images can be so powerful that they manipulate the content of the work, highlighting certain elements over others or openly advocating a certain ideology. At times, there are even 
conto. Além disso, o poder das imagens é tal que acabam por manipular o conteúdo da obra, ao pôr em destaque certos elementos em detrimento de outros, ou mediante a defesa aberta de alguma ideologia. Às vezes, chegam a produzir incongruências entre o texto e as imagens que o acompanham.

Palavras-chave: Tradução. Ilustraçóes. Literatura infanto-juvenil. contradictions between the text and the images that illustrate it.

Keywords: Translation. Illustrations. Children's literature.

\section{Hanna Martens:}

E-mail: hvlmartens@unex.es

\section{José Soto Vázquez:}

E-mail: jsoto@unex.es 